\title{
MENSTRUATION AS MEDICINE
}

\author{
CHRIS KNIGHT \\ Department of Anthropology, University College London, London WCI, England
}

\begin{abstract}
Traditional healing rituals in many parts of the world seem to derive from a model of cyclical renewal provided in the first instance by menstruation. Health is seen as dependent upon a correct balance between polar opposite states such as 'heat' and 'cold', 'dryness' and 'wetness' etc. Nature seems to achieve such balance by alternating regularly between opposites such as night and day, wet season and dry. In this way, periodic 'death' (night, winter etc.) alternates with 'life'. The logic of healing rites is that humans, too, should be able to move through 'death' to 'new life' by keeping closely in tune with wider rhythms of renewal. It is argued here that ideally, women should achieve this by menstruating in synchrony with the moon, which periodically 'dies' and is 'reborn'. Failing this - runs the traditional logic - men themselves must learn to 'menstruate' in some symbolic sense in order to safeguard the rhythms of renewal.
\end{abstract}

\section{INTRODUCTION}

In this paper it will be suggested that shamanistic healing powers derive widely, and perhaps universally, from a model of cyclical renewal provided in the first instance by menstruation*. Using evidence mainly from California, Amazonia and northern and north-western Australia, I will argue that the cultural assumptions underlying shamanism or 'medicine' in these areas run roughly as follows:

(1) health is dependent upon the maintenance of a correct 'balance' between states or forces such as heat and cold, wetness and dryness, blood and fire, kinship unity and sex, or 'rawness' and the state of being 'cooked' - forces, that is, which are conceptualised as polar opposites of the kind which make up the structure of the world;

(2) nature achieves her own health by alternating in a balanced way between these opposites - as between dry season and wet, full moon and dark, day and night, life and temporary or periodic 'death';

(3) the health of the human individual presupposes the ability correctly to reduplicate, within the body itself, these rhythms of periodic renewal;

(4) ideally, women should do this by menstruating in synchrony with one another and with the moon, thus providing a collective social rhythm through which human society can keep 'in phase' with the self-renewing processes of the wider cosmos;

(5) failing this, men themselves must learn to 'menstruate' in some symbolic sense in order to safeguard the rhythms on which human health depends.

\section{THE ORIGIN OF MORTALITY}

Australian Aboriginal myths insistently assert that the finality of death became instituted only when humanity failed to respond properly to the moon. Before that time, death had been only temporary - followed by moon-like resurrection after three or four days. Warner [1] gives a Murngin myth in this vein. In the far-off dreamtiine the Moon and the Parrot Fish had an argument about which was the best way to die. The Moon decided on temporary death followed by resurrection, but the Parrot Fish insisted that this was wrong. The narrator ends his story with the following comment:

When the Moon had had his conversation with Parrot Fish he had wanted Parrot Fish to be like him. He had said, 'Come on and become alive again like me. I can fix you so that you will come alive again.'

'No', said Parrot Fish, 'I want to die and stay dead'.

This is what makes man stay dead and never come back to life. The Parrot Fish was a silly fool.

Berndt [2] gives a similar myth from the same general area; in this, the Parrot Fish is replaced by a female Dugong, the conversation between the two having taken place at a spot known as "the clay pan of the Moonlight", a stretch of beach along Arnhem Bay "outstandingly related to the Moon, his death and his subsequent rebirth”.

\footnotetext{
* The theme of this paper was suggested to me when I learned how, in Papua New Guinea, a man who has encountered a rainbow-snake, believing that he must have been sorcerised and is doomed to die, reverses the normal menstrual taboos and turns for safety to a menstruating woman - anyone will do who cures him either by massage or by giving him "a drink of water in which leaves stained with menstrual blood have been soaked ...". The tribe concerned are the Arapesh as described by Margaret Mead [33], who comments on the remarkable similarities between Arapesh marsalais snake- or lizard-like monsters with 'two heads and two tails', striped red and blue - and the rainbow-serpents of Aboriginal Australia [34]. In Australia and Papua/New Guinea, the monsters are both snakes and rainbows, and live in deep water holes and lagoons. And in both areas, there is the same strange, ambivalent connection with menstrual blood, which both kills and cures. Sickness and sorcery almost throughout Aboriginal Australia are thought to be caused by or through the agency of the rainbow serpent's powers, and when I read Mead's words I was reminded of a practice among the Aranda of Central Australia. There, too, in cases of severe illness, men may reverse the normal menstrual taboos and ask a woman for her blood. "When menstrual blood is not available and a man is seriously ill, blood is drawn from the labia minora and one of the women takes a witchetty grub, dips it into the blood and gives it to the man to eat." The patient's body is later rubbed all over with the blood [30, p. 180; citing 35].
} 
Here is another myth. It comes from the Maung tribe in western Arnhem Land:

Moon and Spotted Possum were once men: but they quarrelled. Possum picked up a sharp wooden yam stick and knocked Moon down. After a while Moon got up, grabbed the same yam stick and hit Possum, mortally wounding him. As he was dying Possum spoke: 'All the people who come after me, future generations, when they die they'll die forever'. But Moon said, 'You should have let me say something first, because I won't die forever. I'll die for a few days, but I will come back again in the shape of a new moon'. As for human beings-we die forever because Possum spoke first [3].

The Dalabon of central Arnhem Land relate this myth:

The Moon and Wallaby disputed as to whose urine their wives should drink. Eventually, both women chose the Wallaby's. Had they chosen moon's urine, people would have grown old, died and then come to life again like the Moon [4J.

The Rembaranga neighbours of the Dalabon tell a cognate myth in which native cat is substituted for the wallaby as Moon's opponent. A final myth from Arnhem Land (Kuppapoingo tribe, Buckingham Bay) tells the story of Nyalindee, a man who lived on an island with his two sons and two wives. Angered with his sons' refusal to feed him properly with the meat they hunted and cooked, Moon enticed them into a fishing net, sewed up the opening and drowned them in a lagoon. In revenge, his wives burned Moon to death by setting fire to his hut:

The fire burned Nyalindee all over. All his skin came off. He was finished.

Then, out of the smouldering humpy, the sisters saw the dead body of Nyalindee come to life. It changed into a shining crescent shape. It grew and grew into a huge glistening sphere. It climbed up into a tall white tree, with white flowers, called gurrerri.

Then, Nyalindee spoke, 'I died. My body, my heart was' burned. My heart, my spirit, is alive. I am here now. You, all you people, you will die. You will die for always. You two sisters, you burned me because I killed my two sons. All right. You will die. You will die altogether. I was alive. I died and came alive again'.

After rising and falling, sleeping and waking several times in different trees, Moon finally found a strong tree by means of which he climbed up into the sky where he has remained ever since as the moon we know today [5]. In this myth it is noticeable that the alternation between death and life is linked with the alternation between water (through which the sons are murdered) and fire (through which the Moon is reborn). It is also significant that the Moon loses all his skin; the theme of rebirth as a 'changing of skins' will be returned to later on.

The above myths all come from Arnhem Land. Two Queensland myths express the same idea, In the first (Kalliduwarry tribe), some old women are eating quantities of gum at the top of a gum tree up which they have climbed, Some young women ask for a share, are refused, and set fire to the tree in revenge, Smelling of burned flesh, the old women ask a succession of groups of men returning from the hunt to carry them back to the camp, but each group refuses on account of the smell. The story continues:

The old women now saw that they must die where they were, so, picking up a large handful of sand and then throwing it down, they called out to the other aborigines: 'You all about will die like that and never get up again'. And all in that camp died in a very short time.

The old women then picked up a very small handful of sand and threw it down, saying: 'We die like that and jump up again in four days', which, their tradition said, did happen,

Immediately after the resurrection of the old women they by some means were able to form the moon [6].

The second version (Clarence River district) runs as follows:

The moon, who was once a man, was speared by another blackfellow, causing the contents of his bowels to come out; this made him very dirty, and his comrades refused to carry him home. The green grass and the ferns, however, took compassion on him and conveyed him to his gunyah. Grass and ferns were originally aborigines and the assistance given by them accounts for their never dying. and springing up fresh and green after being burnt. Had his comrades helped the moon, they would probably have lived forever [7].

It is noticeable that these last three myths share the motif of rebirth through fire,

From Menindee on the Darling River, New South Wales (Wuradjeri tribe), comes the following myth:

One day, two men - Moon and Turkey - were talking when they noticed that old and sick people in the camp were dying. This had never happened before. An argument ensued. Moon wanted all people, if they had to die, to die for only two or three days, after which they would come alive. But the Turkey said, 'No, let them die altogether; then we two can have all the widow women for ourselves'. Then the Moon spoke after deep consideration. 'If you should get sick, you can die altogether, but I won't. I shall die for two or three days and then come up alive again'. It is for this reason that the Turkey, when his time came, like all other blackfellows after this, died altogether: but the Moon never really died. Moon climbed up into the sky from a little hill, which stands straight up and is called Tutelwolangkal, the earthly home of Baiami [8],

\section{RITUALS OF DEATH AND REBIRTH}

The shamanistic healer in Aboriginal Australia is a person, usually male, who has undergone symbolic death and rebirth. Like the Moon, therefore, he embodies both death and life in his own person and can mediate effectively between the two. All healing depends upon such mediation between life and death.

The great initiation rituals of Australia, however, involve not only human death and rebirth. They are conceptualised as forms through which nature itself is renewed, the wet season alternating with the dry, night alternating with day and the new moon alternating with the full. Warner's account of the Murngin Kunapipi ritual is studded with references to the phases of the moon. The first ceremony in the women's camp is supposed to be completed when the new moon appears [1, p. 296]; a month later "when the moon is once more new" (p. 300) the sacred sections of the ceremony - carried on some distance from the women's camp-get under way. A symbolic well is dug and the men enter into it as if 
Menstruation as medicine

returning to the womb. The well is then abandoned, and a crescent-shaped trench is dug in which dancing takes place. "The moon is now full" (p. 302). In the Ulmark ceremony, messengers are first sent away to gather people to attend the ritual; these messengers return when "the moon is about a quarter full in the west..." (p. 322). In western Arnhem Land the ritual coitus section of the Kunapipi - the gudgiga - "is traditionally performed at full moon" [9]. In the Gunwinggu ubar ritual, "the sacred shade is demolished and burnt at full moon"; men are reborn as they dance through the flames [9, p. 131]. The climactic fire ceremony of the Dalabon Jabuduruwa cult should take place on a night when the moon is waning [4]. The Gunwinggu lorgan ritual "is held when the moon is waning"; this is a combined circumcision and mortuary ritual whose basic myth tells of how the Moon decided to die and come alive again, whereas a Pigeon-man decided to die and stay dead, thus introducing death to mankind [9, p. 133]. In the Ooldea region, men 'die' and are 'reborn' in a similar way. The Berndts [10] observed a ritual in which ten men opened the blood-letting phase by piercing their penises in order to produce large quantities of blood. "The actual initiation", noted the Berndts [10, p. 308n], "was held during the period of the new moon".

There can be no doubting the lunar connotations of Aboriginal rites of death and rebirth. The male participants synchronise their activities with the changing phases of the moon; they also symbolically 'menstruate' by cutting their penises or arms. I have discussed the subject of 'male menstruation' in such rituals elsewhere [11]; here I wish to suggest that underlying these rituals is the assumption that it is dangerous to allow human rhythms and cosmic ones to become 'out of phase'. Where women's menstrual cycles cannot be accurately phase-locked to the 29.5 day schedule of the moon, there is the risk, as Lévi-Strauss [12] has pointed out in the context of American Indian belief, that the entire system of interconnecting rhythms and harmonies on which life depends should start to collapse. Having touched on the dangers of cycles which are 'too slow' or 'too fast', Lévi-Strauss (p. 506) continues:

The reason why women are most in need of education is that they are periodic creatures. Because of this, they are perpetually threatened-and the whole world with and through them-by the two possibilities that have just been mentioned: their periodic rhythm could slow down and halt tHe flow of events, or it could accelerate and plunge the world into chaos. It is equally conceivable that women might cease to menstruate and bear children, or that they might bleed continuously and give birth haphazardly. But in either case, the sun and the moon, the heavenly bodies governing the alternation of day and night and of the seasons, would no longer be able to fulfil their function.

The Australian rites through which men are 'reborn' seem to be based on beliefs of this kind. Because women cannot be trusted to menstruate and give birth 'on time', men have had to step in and do the job properly for them. Women's processes of menstruation and childbirth are haphazard, randomised, powerless; they are not properly synchronised either with the moon's phases or with the wider rhythms of society and the cosmos. This problem is overcome, however, by splitting the image of womankind into two. On the one hand, ordinary living women get on with the physical processes of menstruation and birth; on the other hand, mythological Woman - the 'all-Mother', the 'Goddess', the 'Old Woman', 'Kunapipi' - becomes carefully split off and invested with all the social value of which real women are deprived. Menstrual synchrony - a physiological potentiality which I have discussed elsewhere [11, pp. 32-34] - becomes attached to the ideal of womanhood in proportion as it is detached from society's picture of what real women do. And that ideal picture - the image of the 'all-Mother' or 'Goddess' - is a construct manipulated almost entirely by men. When the goddess menstruates in synchrony with cosmic rhythms she does so through men; her blood can only flow when men organise rituals to effect this. In Australia as in America, however, it is still upon menstrual synchrony that health and life are believed to depend. The changing of the seasons, the alternation of night and day and all other cycles of death and rebirth are thought to be dependent on this lunar rhythm.

\section{THE MENSTRUAL MODEL}

To an extent, Lévi-Strauss's point concerning synchrony has been acknowledged by Australianists independently. Certainly there is nothing new in the idea that cosmic and human health are sustained by rituals which work by striving to ensure the harmonisation of celestial and earthly rhythms. Human sexual and reproductive life is an aspect of social life, and Stanner [13] noted long ago that Murinbata rites "were, at the most fundamental level, attempts to make social life correlative with the plan and rhythm of the cosmos". Maddock [4, pp. 132,134] has written that it is "the responsibility of ritual performers to keep natural and social cycles in motion", adding that Australian fertility ritual is "the harmonizing of natural and social rhythms". Ronald Berndt [14] described the north-east Arnhem Land Kunapipi cult as concerned with people's "rhythmic sequence of birth and rebirth", linking the changing of seasons, animal fertility and the human menstrual cycle itself, and Warner [1, p. 397], writing of the Kunapipi, wrote that "when the reproductive cycle does find exptession in the song and dance symbols the seasonal cycle is understood to lie within it as a part of the process of reproduction". The myth of the Wawilak Sisters, of which the Kunapipi is a ritual reenactment, relates to nature 'as a seasonal cycle' [1, p. 405]. The myth views seasonal cyclicity and all other alternations between 'life' and 'death' as the consequences of the menstrual and/or afterbirth flow of Two Sisters at the beginning of time [I, p. 386].

But while the concept of synchrony in a general sense has been acknowledged, the specific notion of menstrual synchrony has been less clearly defined. The first published use of this concept, linking medical and statistical evidence for synchrony in Western contexts with the ethnography of a traditional culture, appears to have been Buckley's [I5] study of menstruation among the Californian Yurok. Buckley concluded (p. 57) that "the women of aboriginal Yurok households menstruated in synchrony, utilizing the light of the moon to regularize their menstrual 
cycles..." If a woman got out of phase with the moon and with the other women of the household she could 'get back in by sitting in the moonlight and talking to the moon asking it to balance [her]' (p. 49).

Buckley's evidence is worth dwelling on because it relates to the theme of responding properly to the moon - the theme of the myths with which this paper began. One evening in 1978, Buckley was invited to the house of an Indian friend for a meal. The house was a modern one within the Yurok aboriginal homelands in northwestern California, close to the Klamath River. Buckley's male friend explained that he would do the cooking since his Yurok wife was 'on her moontime' - in her menstrual period - and they were keeping the old ways as best they could. A back room had been set apart in the modern house for his wife's monthly use; the couple neither ate nor slept together for ten days during and after the flow. The wife explained that she had been instructed in the menstrual laws by her mother's sisters and maternal grandmother - women who were, writes Buckley, "in their times, well-known, conservative Yurok ladies". Her understanding of menstruation came largely from these sources. She began her account of this understanding by telling Buckley that as a foster child in non-Indian homes she had been taught that menstruation is "bad and shameful" and that through it "women are being punished". On her return to Yurok society, however, "my aunts and my grandmother taught me different" (p. 48).

According to the old menstrual laws, a woman should isolate herself during the flow "because this is the time when she is at the height of her powers". Such time should not be wasted in mundane tasks and social distractions, nor in concerns with the opposite sex. Rather, all of one's energies should be applied in concentrated meditation on the nature of one's life, "to find out the purpose of your life". It is a time for the "accumulation" of spiritual energy, the menstrual room or shelter being "like the men's sweathouse", a place where you "go into yourself and make yourself stronger". As in traditional male sweathouse practice, there are physical as well as mental aspects of "accumulation" of spiritual power. The blood that flows serves to 'purify' the woman, preparing her for spiritual accomplishment. Moreover, by focusing full attention on her body and its processes, a woman could make "even the most natural and spontaneous of actions fully conscious and intentional: 'You should feel all of your body as it is, and pay attention"'. The use of a scratching implement so as to avoid scratching the body absentmindedly with the fingers is an example of this (p. 49). In the old days, menstruating women used to go to bathe and perform rituals in a "sacred moontime pond" up in the mountains above the old Yurok village of Meri:p. Practitioners brought special firewood back from this place for use in the menstrual shelter. While many girls performed these rites only at the time of their first menstruation, aristocratic women went to the pond every month until menopause. Through such practice women came to "see that the earth has her own moon time", a recognition that made one both 'stronger' and 'proud' of one's menstrual cycle. Perhaps most important of all, all of a household's fertile women who were not pregnant menstruated "at the same time, a time dictated by the moon", the women practising the bathing rituals together at this time, while the men of the household synchronised their own activities accordingly, using the time to 'train hard' in the household's sweathouse. Women who were in danger of getting out of synchrony used the light of the moon to help get themselves back in phase (p. 49).

Following his visit, Buckley re-analysed the literature on the Yurok and discovered field-notes recording myths, descriptions of ritual and statements from female informants which had been systematically ignored by anthropologists and never published. Much of this material was consistent with his informant's understanding of menstruation as a source of sacred power. Moreover, it appears that male shamanism and sweathouse practices were directly symmetrical with the processes through which women menstruated in order to 'purify' themselves. Just as the women collectively retreated from their husbands and accumulated spiritual power for ten days, so the men used ten days as the standard period for men's 'training'. Like the women, the men bathed, gathered firewood, avoided sexual contacts, ate special foods and let flow their own blood - the men gashing their legs for this purpose with flakes of white quartz. The flowing blood was "thought to carry off psychic impurity, preparing one for spiritual attainment" (p. 51). Men who were in special training to become 'doctors' secluded themselves in the sweathouse and 'made medicine'; Buckley provides evidence that the 'medicine baskets' and dentalium shells used by men to contain their power-tokens were symbolic of the vaginas of women (p. 53). Moreover, elderly Yurok men told Buckley "that intensive male training was always undertaken 'during the dark of the moon', while other sources indicate that this was also the time when the women were menstruating (p. 55). Finally, there is evidence that specific features in Yurok sweathouse construction "permitted accurate observation of yearly solar and lunar cycles in each village" (p. 56), while the women's menstrual houses probably included large communal dome-shaped structures, heated by fires, used for sweating and capable of sheltering several women at a time (p. 55). Buckley (p. 57) postulates an aboriginal culture in which the menstrual synchrony and power of women not only influenced ritual life but had "profound, pragmatic implications as well in dictating the temporal structuring of activities for entire households on a monthly basis". The menstrual 'clock', in other words, was not something purely internal or private to women, but provided a rhythm central to society as a whole.

\section{BARASANA COSMOS}

It may well be that this was also the case at some time in the past in Aboriginal Australia. Before turning to this discussion, however, some further comparative evidence may be drawn upon. In 1979, two years before the publication of Buckley's article, Christine and Stephen HughJones published their study of menstrual ritualism among the Barasana Indians of north-west Amazonia. Parallels between Amazonian and 
Austrialian Aboriginal ritual structures are drawn by the authors themselves [16], and, indeed, it is pointed out (p. 139) that Stanner's [13] account of the Murinbata concept of "the dreaming" "can be read, almost word for word, as an account of the Barasana concept of He". Taking tropical South America as a whole and comparing it with northern and north-western Australia, we find the same preoccupation with snakes and rainbows, the same association between rainbow-snakes and menstruation [17], the same use of quartz and crystals by sorcerers [17, p. 504], very similar myths describing how huge snakes gave birth to the first human beings [18], male initiation rituals in which men 'menstruate' [16, pp. $132,153,184]$, a mythological emphasis on the moon [12, pp. 143-144] and, finally, the belief that the ritual power of men was originally in women's hands [19; 16, p. 127]. These parallels are so precise and remarkable as to suggest some identity of structure at a level deep beneath the surface of consciousness or custom in the societies concerned. If in both cases, as among the Yurok in California, the starting point had been the phase-locking of women's menstrual cycles with the moon, much of the mystery would begin to clear.

In what follows, a description will be given of the mythology and ritual life of the Amazonian Barasana.

\section{He House}

Barasana male ritual life centres around the concept of He wi or 'He House'. Like the Yurok men's 'sweathouse', this seems to be a male counterpart of the menstrual hut or house. He House is a ritual symbolic male menstrual period, lasting three days. Female menstruation "sets women apart in an order which is purely random"; its male symbolic counterpart brings men together in a large social group [18, pp. 155, 159]. The climax of He House is the burning of beeswax in a sacred wax gourd; the wax "has a specific association with menstrual blood" while the gourd is "like a womb containing children"; the melting of the wax produces a symbolic menstrual flow which brings on the annual rains [16, pp. 167, 178]. During the ritual, the novices and others are covered with red paint "identified with menstrual blood" (p. 184); women are not to touch this paint or they "will immediately start to menstruate", their blood being this paint (p. 76). He House is not only a "metaphorical menstruation" [18, p. 153]; it is also "a symbolic act in which adult men give birth to the initiates" [16, p. 132]. In order to give birth, men "must first be opened up and made to menstruate:' (p. 132). The boys to be born are metaphorically 'swallowed' by an immense anaconda snake (p. 218); the boys are made 'dead' by being coated with black paint (said to make the flesh rot); they are arranged in a foetal position (p. 77); they are then reborn and treated like new babies by the men. Finally, they are ritually 'cooked' by being bathed in smoke (p. 83). For about two months after the rite, black paint remains on the initiates, who are subject to rigid dietary, sexual and other restrictions. The boys are said to be dangerous and contaminated "like menstruating women"; any woman who touched the boys in this state would be penetrated by He "in the form of an anaconda" (p. 87).

\section{Woman Shman}

In the beginning, say the myths, water and fire, rainy season and dry, women and man were undifferentiated. Then came "Romi Kumu, Woman Shaman, the prototype shaman from whom all shamans derive their power..." (p. 100). Using her magic vagina, which contained both water and fire, she created the seasonal cycle by first submerging the world in a flood, then burning it in a universal conflagration (p. 263). The rainy season is "the menstrual period of the sky" (p. 179), the rain itself being Romi Kumu's blood. The onset of the rains is associated with the Pleiades and with the Moon (p. 192); among the neighbouring Desana, this is the moment when the huge anacondas rise up vertically out of the water to "assure themselves of the changing seasons" [20]. The shedding of the blood-like rain is conceptualised as a cosmic renewal, a moment of "cosmic skin-change", consistent with the idea that He House "succeeds in renewing the natural processes of the world" [18, p. 156]. The renewal of women, "being associated with the moon, is also associated with the opposition between day and night"; it is equally associated with the alternation between wet season and dry [18, p. 156]. Romi Kumu is old in the evening, yet by painting herself with menstrual blood and then bathing to wash it off she "changes her skin" and becomes young again each morning [16, p. 264]. Seasonal and lunar rebirth or renewal express the same logic in which death is overcome. The myths say that the ancestors of humanity had the chance to remain immortal but lost it by failing to respond properly to Romi Kumu's womb. "I'm not going to eat from your vagina, it is very bitter and smells" was the response of Old Star when offered the gourd of immortality by Romi Kumu herself. Romi Kumu put the magic gourd back between her legs and offered the people an imitation of the real thing [16, pp. 264-265]. This is the gourd used in the ritual of He House, which permits men to be reborn but does not allow escape from death itself. It is said that "the wax gourd used at He House is not the real one but the left-over gourd which gives life but not immortality" (p. 182). The boys who, in the ritual, are coated with black paint and are said to "die" and then "come alive", are said to be following in the footsteps of the Moon, who was the first to die and be reborn in this way (p. 274). Yet the men know that what they do is in some sense only an "imitation" of the real thing. "We were directly told", writes Christine Hugh-Jones, "that He wi is like women's menstruation, but that women really do menstruate while He wi is bahi kesoase, imitation" [18, p. 154]. The women say: "The men make as if they too create children but it's like a lie" [16, p. 222].

\section{The rule of women}

The Barasana myths say that the power of He originally belonged to women, but was then taken over by men. This is one local aspect of the classical myth of the Amazons - women who once fought and held power like men - from which the river Amazon itself derives its name. The Barasana argue that Romi Kumu in ancestral times possessed the power of $\mathrm{He}$ and all the ritual equipment-including sacred 
flutes - which men use today. One myth [16, pp. 264-265] states that Romi Kumu's own vagina was the source of He, and that all men managed to take from her was an imitation, as has been seen. Another myth says that Romi Kumu had no right to the He and sacred paraphernalia: she herself had stolen it from men, who then chased after her, took it back from her and punished her by making her and all other women menstruate from that moment on (p. 266). For comparison, here is another Amazonian 'rule of women' myth, from the Mehinaku [21]. The narrator is (as is usual) a man:

In ancient times the women occupied the men's houses and played the sacred flutes inside. We men took care of the children, processed manioc flour, wove hammocks, and spent our time in the residences while the women cleared fields, fished, and hunted monkeys. In those days, the children even nursed at our breasts. A man who dared enter the women's house during their ceremonies would be gang-raped by all the women of the village on the central plaza.

One day the chief called us together and showed us how to make the bullroarers to frighten the women. As soon as the women heard the terrible drone they dropped the sacred flutes and took over the men's houses. Today if a woman comes in here and sees our flutes we rape her. Today the women nurse babies, process manioc flour, and weave hammocks, while we hunt, fish, and farm.

A Mundurucu myth follows the same pattern [22]:

Long ago, three women were walking in the forest when they heard music that seemed to emanate from a lagoon. They investigated, but saw nothing but fish swimming in the waters. Each woman caught one of these fish, and each fish immediately turned into a sacred flute. The women played these instruments, and so strong was the power of the music that it enabled the women, on returning to their village, to occupy the sacred men's house and compel the men to live in ordinary dwellings instead. From then on, the women did little but play on their flutes all day long, while the poor men had to make manioc flour, fetch water and firewood, and care for the children. The men's ignominy was complete when the women visited them at night in their dwellings in order to force their sexual attentions on them ("Just as we do to them today", as a male informant explains). But one day the men, as hunters, went on strike and refused to provide meat until the women had surrendered their flutes. Frightened of angering the spirits of the game animals, the women complied and the men seized power. That is why sex-roles are as they are today.

Returning now to the Barasana, Christine Hugh-Jones [18, p. 155] notes that the myth of the primordial 'rule of women' is true in the sense that it describes with accuracy what men in their rituals actually do, which is to "appropriate the ultimate female powers of sexual reproduction for themselves..." He House is "a social occasion in comparison to menstruation", which "sets individual women apart in an order which is purely random..." The symbolic potency of menstruation, in other words, and its synchronisation with wider rhythms, is something of which women are genuinely robbed in the course of rituals which (a) unite men in the course of their pseudo-'menstrual' periods and (b) isolate women when they menstruate in real life. Nevertheless, the knowledge that this is not 'natural' is important, too. Women's He, as everyone knows, "is in their bodies and in their hair whilst that of the men is embodied in cultural symbols" [16, p. 251]; women's He is 'original' and 'real' whilst men's is "like a lie" (p. 222). Women's involvement with immortality and cyclical renewal is guaranteed by the moon and the menstrual cycle itself, whilst men can share in immortality only through sustained collective effort - and, even then only with partial success. The myths say that when men foolishly declined Rami Kumu's offer of nourishment from her vagina, snakes and spiders stepped in, ate from the "smelly" receptacle and acquired the power to change their skins instead of dying. Men were left only with the artificial wax gourd and since then, when they have died, they have not come back to life (pp. 264-265).

\section{AUSTRALIA: THE MURINBATA}

Although Barasana men, when they die, die permanently, Barasana youths, in being initiated, "die" only to be "reborn". When the youths have been "rotted" with black paint and are then "sat down ... in a foetal position with their knees drawn up to their chests" [16, p. 77], they are said to be in an extremely vulnerable condition. This condition is "compared to that of crabs and other animals that have shed their old shells or skins" (p. 120). Menstruation, like He House as a whole, "is an internal changing of skin" (p. 183), so that the boys in their vulnerable condition are like crabs or menstruating women in the process of self-renewal.

This paper began with a selection of Australian myths linking the origin of death with man's failure to respond appropriately to the Moon. Here are two slightly different variants from the Australian Murinbata tribe [13, p. 15]:

(i)

Crab was mutjingga (very old woman). She was very sick. Everyone thought she was dead. They buried her in a hole. But she was not dead. She stayed there about five days. She made a new shell and left the old one in the ground.

Crow was there waiting. The people were crying. Yau! Crab was there! The old woman came back. Everyone was happy. Crow was angry. He said to Crab: 'That way takes too long. This is what we people must do'. He plucked out Crab's eyes and died.

(ii)

Crow and Crab argued. Crow asked Crab which was the best way to die. Crab said: 'This is what we people should do. She went into a hole. She stayed there changing her shell. She made a new shell. She threw the old one away'.

Crow was there waiting. He went to search for Crab. He looked in the hole. He said: 'This way takes too long. It takes too long to get strong this way'. He went back to the waiting-place. Crab stayed in the hole until her shell was thick and strong. Then she came back. She said to Crow: 'That is what we should do'. Crow said: 'No, it takes too long. Someone might come and kill (hurt) us. There is an easier way to die. This is what we should do. He rolled his eyes, fell down backwards, and died at once.

Crab took water and poured it on him. 'O, he is dead'.

It is important to understand that these are not mere incidental stories or tales for the amusement of children. The Murinbata really do insist that crabs do not die if left unmolested, but change their shells when they grow old and renew their youth and strength. It is firmly believed that the same possibility once existed for man, but was spoiled by Crow. 'The myth", writes Stanner [13, p. 155], “was the standard 
answer to questions about the ultimate why and wherefore of death: Crow's decision determined all men's fate thereafter". Stanner notes, too, that the story of Crab and Crow is merely one particular way of expressing a theme consistently expressed in all Murinbata mythology - the theme of a "wrongful turning in life" (p. 40) at the beginning of time. Perceiving the world through the lens of their myths, the Aborigines see signs and evidences everywhere "that something happened long ago, something mysterious, and heavily consequential for ... human life ... " (p. 63). Mutjingga, the "Old Woman", appears in the above myths as a Crab who was blinded or repudiated with tragic consequences for humankind. In another myth central to the Murinbata rite of Punj - $a$ ritual of 'death' and 'rebirth' - she appears as a primordial Mother who swallowed ten children entrusted to her care. Tragically, she had to be killed in order for the children to be rescued from her womb. This myth explains the initiation rite in which boys are 'swallowed' and 'regurgitated' today, but the Old Woman's death "was, and still is, a matter of sorrow: 'she should have lasted a long time'; 'the people did not want to kill her'; 'they wanted to keep her alive for Punj'” (p. 43). The loss of the oncepowerful 'Mother' is felt to have been 'irreparable', and the artificial paraphernalia through which men in their rituals now recall her presence is considered sadly inadequate. "Because she died", men say, "men now have only the bullroarer, which was made in order to take her place i.e. stand for her and ... to be her emblem, symbol and sign" (p. 43). In this myth, as in so many other myths of the Murinbata, the overwhelming sense is "that there has been some kind of 'immemorial misdirection' in human affairs, and that living men are committed to its consequences" (p. 40). Immortality has been lost, but men in their rituals still do the best they can.

It is clear from what has been discussed that the moon dying and being reborn, the crab, snake or spider which changes shell or skin as an alternative to permanently dying, and the men or boys who in initiation rituals undergo symbolic 'death' and 'rebirth' are symbolically one and the same. It is also clear that in at least some cases, there is a conscious link, expressed in the mythology, between such 'temporary death' or 'skin-changing' and the physiological process of menstruation. This is not quite as explicit in the literature on the Murinbata as it is in the ethnography on the Barasana. Yet all the basic elements are there: the theme of death and rebirth, the connection of this with the 'shell-changing' of a Crab or 'Old Woman', the belief that male initiation ritual preserves at least an aspect of this logic of perpetual renewal, the notion of the robbery of ritual power from women or Woman - and the idea of a 'wrong turning' made at the beginning of time, and as a result of which men today possess something less than the immortality of which they would otherwise have been assured. In the rite of Punj, moreover, the novices are smothered in the "Old Woman's" blood - in reality blood shed by men - as they are "swallowed" in order to be "reborn" (p.7)*.

*Luc de Heusch [36], writing about the moon-menstruation-rainbow-serpent complex in central Africa, describes myth as "a symbolic drama utilizing contradictory traits in nature and culture to portray the great cosmological rhythm upon which life depends". 'Divine kingship' in Africa as elsewhere is built upon the assumption that the daily, monthly and seasonal renewal of the earth is a central responsibility of the King or Queen, the making of rain or the controlling of floodwaters presupposing the ability of the ruler to harmonise earthly and cosmic rhythms. De Heusch (pp. 365-367) shows how the prolonged menstruation of a Queen and the bleeding of a decapitated King correspond to one another in the myths; how both blood-streams merge with the image of a rainbow, and how the flow itselfs ends the dry season and brings on the annual rains. Human sacrifice, in other words, has as its core the notion that human blood must periodically flow if the rhythm of the cosmos is to be sustained, this concept itself being a transformation of the belief in a correspondence between menstrual renewal and the renewal of the earth and the sky.

The link between all this and shamanism in Aboriginal Australia may not seem immediately apparent. Stanner [13, pp. 2-21], however, in his study of the Murinbata rite of Punj, was powerfully impressed by what he termed "some very striking resemblances between the form of a bullroarer ceremony and the form of sacrificial ceremonies in more developed religion". In a sacrifice, he writes, a creature or a person is first set apart or made 'sacred', then immolated or destroyed in an act which may be 'bloody or unbloody', and finally - through this destruction - transferred to another realm from which benefits are believed to be received in return, these benefits being shared communally and treated as the sacrificed person or creature in another form (pp. 3-4). Stanner (p. 4) argues that the ceremony of Punj - "the highest rite of the Murinbata" (p. 25) - "conforms generically to the operational character of sacrifice" as just defined. The boys, in being ritually 'killed' in offering to 'the Old Woman' or 'Mother', are human sacrifices whom this mythological being devours. They are "immolated by blood", deprived of their former identity, metamorphosed in the womb of the Mother and then "returned to life with a changed nature", a process of communication between humans and the spirit world from which shared benefits are believed to ensue (p. 14). It was rites such as this which Stanner (p. 139) described as, "at the most fundamental level, attempts to make social life correlative with the plan and rhythm of the cosmos". It was upon such harmony between social and celestial rhythms that "the continuation of a plan of life, given once-for-all in The Dreaming, but in continuous danger of corruption" (p. 4), was thought to depend.

Sacrifice is a kind of 'killing' which leads, not to death, but to the renewal of life. The divine Queen in Africa menstruates and disappears from view; she is in her period of "temporary death", from which she emerges having renewed her own life and that of the world she rules. The divine King is decapitated and his blood flows out; he then reappears in the person of his successor and the kingdom is renewed. The boys in the Murinbata rite of Punj are 'killed' and bloody; they reappear, transformed, and the world comes back to life. In these different modes of 'sacrifice' or 'renewal', the Yurok feminine experience that "the earth has her own moontime" [15, p. 49], harmonized with a flow of human blood, may be discerned. This is a logic central to mythology probably throughout the world. Certainly it is true for the cultures touched upon here, and there is no reason to suppose that the net could not be cast further afield. 


\section{NORTH-EAST ARNHEM LAND: THE EARTH'S MOONTIME}

In north-east Arnhem Land, Australia, there is uncertainty as to whether women's or men's blood should be used to bring on the annual life-renewing rains. Or rather, both methods are adopted by neighbouring tribes, and the alternatives are present to everyone's mind. This is what makes the Arnhem Land case so interesting: there is no need to speculate on the possibility of a connection between female menstruation and rites in which men shed blood, since the alternatives are present in the culture as different ways of doing the same thing.

Religious life in north-east Arnhem Land [23, p. 4] "centred on procreation, on the renewal of human beings and of the natural species, and on the continuity of family and community life through mythic intervention and guidance". The mythic beings who intervened to ensure life's renewal included, perhaps most centrally of all, the two Wawilak Sisters who, in the beginning of time, set up seasonal alternations and the alternation between life and death by menstruating or shedding afterbirth blood together into a sacred waterhole from which floods and rains then emerged. "The cycle of the seasons with the growth and decay of vegetation, copulation, birth and death of animals as well as man, is all the fault of those two Wawilak Sisters", as men choose to put it [1, p. 385]. If the Sisters had not menstruated into the pool, the Rainbow Serpent- personification of the great annual floods and storms - would not have appeared, and neither would there have been male and female, copulation and birth, life and death (p. 385). "After they had done this wrong", however, "they made it the law for everyone". Menstruation is 'wrong'. It is 'polluting' and 'negative' like the rainy season or like death itself. But- like death - it is a necessary part of the scheme of things. As Warner (p. 386) puts it, the "swallowing" of the earth by the rainy season "is known to be caused by the wrong actions of the two Wawilak women" in "profaning" the sacred waterhole with their blood:

This is not considered an unmixed calamity, however, because the rain and water bring the plants and bulbs and flowers which are consumed directly by man or provide pasturage for kangaroo, opossum, and other animals eaten by man, In' other words, the Murngin see the snake's swallowing the women and animals [that is, the flood's engulfing of the world] as necessary and part of the scheme of things, and their testimony clearly demonstrates the casual relation between the actions of the Wawilak women and the seasonal cycle.

Seasonal cyclicity is triggered by the menstrual flow.

"The outstanding phenomena", writes Warner (p. 378) of north-east Arnhem Land, "are the great seasonal changes which produce heavy rainfall and floods for five months, and for seven months an extremely dry season in which there is no rain and many of the streams, lakes, water holes and inlets dry up". During the period of the rains - from November to March - movement and communication is extremely difficult, partly because much of the countryside becomes submerged in a shallow sea of mud and water, the Aborigines becoming cut off from one another on little islands and portions of higher ground, partly because tropical vegetation springs up everywhere, so that the paths and most of the country are covered with giant spear grass growing to twelve or fourteen feet in height. In this wet Australian 'summer', therefore, the Aborigines, prevented from all but a minimum of travelling, socialising or hunting, live with "a scarcity of food, unpleasant physical surroundings, a minimum of creature comforts, small horde groupings because of food scarcity, little social activity, as well as the possibility of actual hunger, sickness and privation, and even death from floods". Small wonder, then, that the Aborigines think of the wet season as representing "comparative ill-being" (p. 404). From May to September, by contrast, there is usually no rain at all. The inland lakes dry up, streams disappear and many of the sacred clan water holes become empty. Nevertheless, enough water remains to sustain life, and the disappearance of the lakes and much of the thick vegetation makes travel and social gathering possible once again. Sexual activity, which had been restricted to a minimum in the wet season owing to general depression and the small size of band or family groups, now begins to pick up as wider opportunities for encountering partners arise. The sea in this region "abounds in dugong, turtle, fish, crayfish, shellfish, oysters, and crabs", while inland, on the plains and in the jungles, "there are wildfowl, emu, wallaby, kangaroo, and smaller animals, fruit, nuts, vegetables, berries and a large variety of other bush foods, with quantities of fresh-water fish and crocodiles in the streams and rivers" [14, p. 2]. In the dry season this abundance of food can be taken advantage of, and provides the possibility of sustaining nutritionally the large numbers of people who gather together at this time for ceremonies and rites. The dry season, in short, means "a plenitude of foods, easy and pleasant surroundings and ample creature necessities, large horde groups, intense and enlarged social activity, and pleasant and exciting behaviour, such as hunting and harpooning..." The Aborigines think of this season in 'positive' terms [1, p. 404].

The wet season, then, is 'death'; the dry season, 'life'. But death is the precondition of life in the scheme of things which the Wawilak Sisters, by their blood-flows, set up. Wet season or 'death', in this context, corresponds to the moon's darkness or the menstrual flow: it is the condition of perpetual self-renewal. Menstruation means no sexual adventure, no travel, no food: it means everything which, on another level, the rainy season implies. Women are secluded: 'swallowed up' in their own blood, withdrawn into themselves or into their own small family groups. But this withdrawal into the self is a necessary part of the scheme of things, for it is an accumulation of inner strength, like sleep. The skies darken, the eyes close, the withdrawal into the 'Dreamtime' begins. The rains fall, the floods spill over the landscape, the blood-streams flow - all these blotting out sex, feasting and adventure as they blot out the sun. Seasonal cyclicity, in other words, is conceptualised entirely in menstrual terms, being thought - as Warner (p. 397) puts it - to "lie within" the menstrual cycle as "a part of the process of reproduction". The "concepts of the reproductive cycle and seasonal alternation", Warner 

continues (p. 398), "state the same generalisation and are given the same symbols in the [Wawilak Sisters] myth". The seasonal 'flood' is equated with the menstrual 'flood' or 'flow'; the 'dry season', by contrast, connotes marital sex and cooking-fire. Menstrual alternation between blood and fire, rain and sunlight, wet season and dry is taken to be a single, indivisible, life-force or principle, only partially and inadequately connoted by the snakes, rainbows and other symbols which refer to it in language, rite and myth.

It is not surprising, then, that in this part of the world - as in so many others - rain-making ritual should involve the shedding of blood. In the love-songs of Goulbourne Island, men are depicted having intercourse with girls as a means of bringing on their menstrual flows which are essential to the coming of the rains. "North-eastern Arnhem Landers", as Berndt [23, p. 68] writes,

saw this as an observable progression of inevitable events: coitus among the palms; the onset of the menstrual flow; the attraction of the clouds; the arrival of the Lighting Snake, drawn by the smell of the blood; and finally the coming of the monsoonal season.

There is the sound of thunder - voice of the great Snake - "drifting to the place of the Wauwalag Sisters" (p. 67). In the Rose River song-cycle [23], men bring on the rains by deflowering virgins, whose flows of blood entice the hungry Snake which emerges from its hole, flashes along in streaks of lightning, eats the feminine blood, heads towards "the Vagina place, the place of the Snake" (pp. 100101 ) and soon bursts out in rain and storms. In the coastal songs, the connection between menstrual blood and monsoonal rains is conceptualised through images in which the blood pours down from women's vaginas into the 'reproductive organs' of the land itself - the life-giving water holes, streams and inlets on which fertility depends - and flows thence into the sea, and into the clouds which rise from the sea, returning later transformed, in the shape of the dark monsoonal storms and floods which 'swallow' the earth.

All of this illustrates how the Yurok idea that the earth 'has her own moon time' links in with the Australian Aboriginal idea that human and nonhuman cycles of renewal were mutually supportive and sustainable through the same rites. This in turn implied that the landscape itself beat to human reproductive rhythms. "Physiographic features of the countryside", as Berndt [23, p. 7] puts it, "were likened to male and female genitals", so that imprints in rock told of a mythic act of coitus, a sacred waterhole would "symbolize a vagina", "a shining white substance on a rock surface" might "represent semen" and so on. Everything natural, in other words, was conceptualised in human terms, just as everything human was thought to be governed by natural rhythms. Berndt (p. 12) phrases this by writing that the Aborigine

projected his own belief system on to the environment in which he lived. He saw within it the same forces operating as he identified within his own process of living.

But 'projection', I think, is not quite the appropriate word. If the moon, the tides, the days and nights, and the changing of the seasons really did all interweave with the rhythms of human productive and reproductive life, then thyre was little subjective or illusory about such Aboriginal beliefs. If, for example, the coming of the annual rains really did transform the structures of Aboriginal kinship and sexual life, forcing all to live secluded in small groups [1, p. 404], or if menstruation really did coincide with the darkness of the moon, secluding women simultaneously everywhere, eclipsing marital life and cooking-fires like a great shadow across the sun, then it would seem that nature was projecting her logic into humanity as much as the other way around.

I see no reason to discount the Aborigines' own beliefs that, in their rituals, they were drawing upon natural rhythms and harmonising with them to the advantage of both nature and themselves. It was not that man was dominating nature; but neither was it that human society stood helpless in the face of nature's powers. Rather, human society was flexible enough and sensitive enough to tune itself finely to the rhythms of surrounding life, avoiding helplessness by replicating internally and through symbolic forms nature's rhythms. Nature was thereby humanised, while humanity yielded to this nature. If the hills felt like women's breasts [24, p. 151], if rocks felt like testicles, if the sunlight seemed like sexual fire and the rains felt like menstrual floods, then this was not mere 'projection' of a belief-system onto the external world. This was how things felt because this was how they were - socially, and therefore for humans in reality.

We have forgotten how to feel such things, and perhaps many of our own illnesses stem from the fact. "The first thing a blackfellow notices about a white man when he sees him for the first time", writes Ryan [25], a European adopted by Queensland Aborigines in his childhood,

is that he is deaf (momba), that he does not take notice of things around him, and he does not 'feel' anyone that is near hilJl His bodily senses have been out of use for so long that they do not function any more.

Yet if their myths reflect their state of mind, do not the Aborigines themselves feel that at some moment in their past, even they became deaf to the suggestions of the moon? However developed their senses by comparison with those of Europeans, is not a sense of 'Ioss' - of "a wrongful turning in life" or a failure to keep in touch with the ultimate sources of being - felt keenly by the Aborigines even to this day? In north-east Arnhem Land, men seem uncertain whether women's blood or men's is the best vehicle for ensuring communication with the reproductive powers. The evidence is fragmentary, but the picture which suggests itself is of a culture which still knows the possibility of menstrual synchrony of the kind which Buckley in California describes. Where men busy themselves cutting their penises or arms in order to let flow the ancestral Sisters' blood, it is in an attempt to restore lines of communication - the 'feeling' of people for one another and for the moon - which were severed in the distant past. 


\section{THE SHAMAN}

Yurok shamanism, as has been noted, centres around the institution of the sweathouse, male counterpart of the women's menstrual shelter, while Barasana shamanism centres around male menstruation or He. In Australia, as in much of Amazonia, the 'state of betwixt-and-between' in which both women and shamans exist can be connoted equally by rainbows and snakes. Rainbows are 'betwixt and between' sunshine and rain, dry season and wet, earth and sky, while snakes, as skin-shedders, may be believed to be 'betwixt-and-between' one life and the next*. Barasana mythology, as has also been seen, holds that snakes, like spiders or other shellchangers or skin-changers in nature, derived their immortality from Woman Shaman's womb. This womb produced alternately menstrual blood and fire, wet season and dry - the skin-changing of the cosmos - while it is believed that women as such

are semi-immortal: through menstruation, they continually renew their bodies by an internal changing of skin- hence they live longer than men-and through childbirth they replace themselves with children. These processes are thought of as being akin to the succession of seasons and the growth of animals and plants in the natural world. The key to female creativity is seen to lie in the fact that women, like the world of nature, are periodic and cyclical.

This "periodicity of women, and the immortality it suggests", are "emulated' by men" in the course of rites such as He House [16, p. 250]. These rites are necessary because men failed to choose the genuine immortality once offered to them.

Throughout Australia, the shaman or 'clever-man' is one who has symbolically 'died'. A menstruating woman 'dies' to marital and domestic life simply by bleeding. The blood itself transports her to a different world. When men go through such experiences, the symbolisms become more complex, but their meaning and substance remain the same.

In western South Australia, the aspiring shaman is put in a waterhole, where a mythical snake swallows him whole, but later regurgitates him in the form of a baby which flies into the air and falls down beside a certain rock-hole. After a long search, he is found by the doctors in charge of the initiation, and is restored to man's size by being 'sung' in the midst of a circle of fires. After a period of seclusion and converse with spirits, he is red-ochred and treated as a corpse. Then the head doctor ritually breaks his neck, wrists and other joints by marking them with a magic stone. Into each mark or cut, and also into his stomach, the doctor inserts lifegiving shell, after which the postulant is 'sung' and revives, now full of power [26].

In the Northern Kimberley at Forrest River, almost at the other end of the continent,

an old doctor takes the postulant, reduced to the size of a baby, to the sky either on a cord or on the rainbow which serves as a rope. Reaching the sky, he throws him to the sky-land, thus "killing" him. He then inserts in him mahan (quartz-crystals) and little rainbow-snakes, which he can obtain in a waterhole at the foot of the rainbow. Bringing the postulant back to earth, he inserts more mahan into him through his navel, after which he wakes him up with a magical stone [26, p. 22].

The quartz and pearl-shells used in such rituals are connected with the rainbow serpent, probably, as Elkin (p. 33) points out, because of "their reproduction of the colours of the rainbow ... ". In Queensland among the Turrbal the special pieces of quartz which the medicine-men possessed were obtained from deep pools, creeks and similar places, where they dived for it. Targan, the spirit of the rainbow, was supposed to have "vomited them out and deposited them in such places" (p. 93). The medicine men knew where to dive for them, namely "where the rainbow ended". They were also supposed to be able to cut the rainbow off where it was held to the riverbottom, and "to send rain and squalls", in addition to travelling both underground and through the air at will.

In New South Wales, among the Wuradjeri, medicine-men are associated with Wawi, a serpentlike creature who lives in deep waterholes and burrows into the bank, where he makes his den. A medicine man wishing to see him

paints himself first with red ochre, and after a shower, follows the rainbow, the end of which rests over the water-hole. He dives under the bank, and finds Wawi, who takes him to his den and sings him a new corroboree, which he brings back to the clever men of the tribe [26, p. 87].

Harney [27] records the words of a Waddaman (Northern Territory) medicine-man or kuran. His father had been a great kuran, and often would go into the hills during big ceremonial gatherings and, with the other old men of the tribe, "would talk-talk big about the

*The Trio Indians - a Carib-speaking group in the Amazonian region, between Brazil and Surinam - divide the world into two categories, nature on the one hand, culture on the other. Into the 'nature' category come men, male activities, the area outside the village, the unknown and the forest; under the heading of 'culture' come women, female activities, the area inside the village, the known and the home. The ethnographer Riviere [37] describes these opposite poles into which the universe divides, and then makes a comment which I will quote in full:

Now the mediators between these oppositions seem to operate in one of two ways; either they act as means of communication between the polar terms, or else they tend to strengthen one to the detriment of the other. An obvious example of the former is the shaman, whose mediating role is almost universal, and the Trio shaman is no exception to this. He stands between people and spirits, he is of the earth but can visit the other cosmic levels, he is both curer and killer, depending on whether he is inside or outside. Temeta succinctly summed up the shaman's position when he said that a shaman is like a menstruating woman, an apt simile which stresses the state of betwixt-and-between in which they both exist....

Riviere's comment that the shaman's "mediating role is almost universal" can, I think, be extended. A purpose of this paper is to suggest that the simile used by his informant Temeta - that the shaman is "like a menstruating woman" - applies equally to the culture areas with which we are concerned. The shaman, as Temeta explains, is not in business to stress one-sidedly one or other of the polar states or forces into which the world divides. His task is to ensure an effective balance, flitting between them just as a menstruating woman flits 'betwixt-and-between' this world and her seclusion. 
latest cures and the best medicines...". When the informant grew up, he was gradually encouraged to join the select group. Then, one day, as he was walking through thick scrub, he heard a beating of sticks and, looking around, saw a huge devil-devil with big eyes dancing towards him through the trees. Behind him were the dreaded Moombas, beating the tap-sticks of the monster's dance. The informant felt he could not run away, since "no one can run away from evil". It had to be faced. A bitter fight ensued. In the course of this, "somehow I been kind of die"; he had been tied up in a big bag and dangled from a tree and then released, whereupon "a big rainbow water-snake came up out of the sky arid swallowed me up ... “. He swam around in the snake's huge' belly for a while until he remembered that he possessed a white man's pen-knife:

...so I opened up that knife to cut my way out of that big snake and covered with slime, I crawled over to a meat-ant's nest so that they could clear the mess from my body.

The dreaded Moombas - people "who remove the life-essence from the tribespeople" - now welcomed him and befriended him as one of theirown, whereupon he fell asleep and woke up to realise "that this was proper blackfellow business and I was a kuran that could make people die with my songs, and by others could I make them alive once more".

\section{THE WOGEO CASE}

The points which have been made in this paper are not entirely new. Anthropologists in the past have frequently noted that male initiation rites - particularly those involving subincision or periodic bleeding - are male attempts to imitate women's processes of menstruation and birth [3, 28-30]. "It is now quite clear", wrote Róheim in 1945 (p. 174), "that the men who squirt blood forth from their subincised penes are playing the role of menstruating women". "Certainly the evidence points in this direction", the Berndts [3, p. 145] later confirmed. Gould [31] writes of the operation of subincision in the Australian Gibson Desert as "fantastically painful": the "victim nearly passes out". But in the past it has seemed something of a mystery to understand why men were willing to pay such a price in order to 'menstruate', particularly if, as has usually been assumed, it is precisely female menstruation which most of all symbolizes women's exclusion from ritual sanctity and power.

One of the most explicit statements of the general problem is to be found in Hogbin's book, "The Island of Menstruating Men" [32]. "The technique of male menstruation", writes the author of the islanders of Wogeo,

is as follows. First the man catches a crayfish or crab and removes one of the claws, which he keeps wrapped up with ginger until it is required .... From dawn onwards on the day that he has fixed he eats nothing. Then late in the afternoon he goes to a lonely beach, covers his head with a palm spathe, removes his clothing, and wades out till the. water is up to his knees. He stands there with his legs apart and induces an erection .... When ready he pushes back the foreskin and hacks at the glans, first on the left side, then on the right. Above all, he must not allow the blood to fall on his fingers or his legs.

When "the sea is no longer pink" he walks ashore, wraps his wounded penis in leaves, dresses and returns to the village men's club, in which he remains secluded for two or three days. "Sexual intercourse is forbidden till the next new moon..." (p. 89).

Hogbin notes that men "are not called upon to menstruate every month" - otherwise the sexual prohibition "until the next new moon" might rule out sex for most of the time. "But it is argued", he continues (p. 91), "that they ought to be regular and never wait too long". The majority, nevertheless, "delay until sickness reminds them of the need to act". When "an illness has failed to respond to ordinary magical treatment", then the diagnosis is that the patient has been having too much sex. For this illness, "there is but one remedy", an immediate gashing of the penis to remove the "impurities" arising from contact with the opposite sex. "The salutary effects of penile surgery", Hogbin writes,

are said to be immediately observable. The man's body loses its tiredness, his muscles harden, his step quickens, his eyes grow bright, and his skin and hair develop a luster. He therefore feels lighthearted, strong and confident. This belief provides a means whereby the success of all perilous or doubtful undertakings can be guaranteed. Warriors make sure to menstruate before setting out on a raid, traders before carving an overseas canoe or refurbishing its sails, hunters before weaving a new net for trapping pigs (p. 91).

The philosophy underlying all this is that women possess an extraordinary marriage-regulating power. Any husband would hesitate before imposing on his wife because:

All she has to do by way of retaliation is to touch his food when next she menstruates and thereby inflict him with a fatal illness (p. 86).

Menstruation is the periodic antithesis of marital sex or contact, and it is this which is so healthy for women. Marriage is not permanent: it is a relation broken and renewed each month. Sexual desires and temptations are strong, and the need to abstain from sex periodically may be overlooked as a result. But every evasion of the rules, every drift towards structurelessess in marital life, every over-emphasis on the marital bond, brings "disease and misadventure" to all concerned. Both men and women are therefore in constant danger of sickness through contamination with the opposite sex. "The females, however", continues Hogbin (p. 88),

are the more fortunate in that they are regularly freed from contamination by the normal physiological process of menstruation, when the alien elements flow away of their own accord. The males, on the other hand, are obliged to take positive measures to ensure such a periodic disinfection.

The warriors who "make sure to menstruate before setting out on a raid", like the canoe-travellers and hunters who act likewise, are cleansing themselves of the contamination which stems from an excess of marital life, performing artifically the spouse-repelling function which women perform with each menstrual flow. 


\section{MENSTRUATION AS MEDICINE}

All over Australia, as throughout much of the world, traditional 'healing' and 'curing' involves the sucking out from the patient - or the extraction in some other way - of 'contaminations' associated with 'blood'. The use of leeches in our own culture continued until recent times. At first sight, it seems that traditional attitudes towards the blood of women and men are inconsistent: it is poisonous in one context, curative in the text, polluting in one setting, spiritually cleansing in another. In this paper, I have attempted to unravel the consistency at a deeper level in all of this. Periodic menstrual seclusion - the periodic 'death', as we might put it, of marital life and sex - is preferable to dying once and for all. The Yurok woman who, in her modern house, retreats into the menstrual room for ten days, is 'dying' to her husband sexually in order to return to marriage refreshed and renewed. Women whose 'moon time' is invaded have no such time for renewal. Life then becomes an undifferentiated continuum, an unending sameness of function and role, cut off from the cyclicity and alternation which alone can promise renewal. And with the spiritual death of womankind, comes the threat of stillness and death for all. The Yurok Indians who are attempting to preserve their old 'law' are fighting to retain some link with a past which even the Australian Aborigines can remember only through their myths. It is a past in which, as Lévi-Strauss [12, p. 180] has phrased it, the rhythms of human self-renewal "are linked to the main cosmic rhythms: menstruation (les règles) accompanies the moon's phases; pregnancy lasts for a fixed number of lunar periods; the alternation of day and night, the order of the months and the return of the seasons belong to the same system". From the perspective of this system, any infringement of the menstrual rules would endanger "the social as well as the cosmic order" by producing a "state of anarchy in which regular alternation of day and night, the phases of the moon, feminine menstruation, the fixed period for pregnancy and the course of the seasons did not mutually support one another" (p. 222). The Barasana resort to their rituals from a feeling that "human society is in danger of becoming separated from, and out of phase with, its generative source" [16, p. 249]. The Karadjeri in Western Australia let their blood flow in fertility rites since the reproduction of parrot fish requires "The harmonizing of natural and social rhythms" [14, p. 134]. Finally, Warner [I, pp. 402-403] sums up the matter perfectly when he writes of the Murngin:

It is felt that nature, inextricably organized on the pattern of man's social organization, needs purifying as man does, since both are in the same social category, and when man 'keeps from being sick' he at the same time keeps nature from being sick. The rituals keep both man and nature well and strong and allow them to reproduce and the fertility cycle of both to continue.

Modern Aranda blame the dearth of life nowadays in central Australia on the lapse of the rites their forebears once performed [14, p. 134]. It is the same belief here as elsewhere in the traditional world. It was always known that were men or women to remain 'sick'were they to forget their rituals, stay with their spouses, repudiate the moon's blood and make of marriage not a recurrent honeymoon but a permanent, never-ending bond-then, for humanity as for all life on earth, death would remain permanent, too.

\section{REFERENCES}

1. Warner W. L. A Black Civilization, rev. edition, pp. 523-524. Harper, New York, 1957.

2. Berndt R. M. A Wonguri-Manjikai song cycle of the Moon-bone. Oceania 17, 19-20, 1948.

3. Berndt C. H. and Berndt R. M. The World of the First Australians, p. 36. Angus \& Robertson, London, 1964.

4. Maddock K. The Australian Aborigines, p. 159. Penguin, Harmondsworth, 1974.

5. Robinson R. Aboriginal Myths and Legends, pp. 152-157. Sun Books, Melbourne, 1966.

6. Fraser A. The moon myth. Sci. Man Aust. Anthrop. J. 2, 194, 1899.

7. McDougall A. C. Manners, customs and legends of the Coombangree tribe. Sci. Man Jl R. Anthrop. Soc. Aust. 4, 63, 1901.

8. Berndt R. Wuradjeri magic and "clever men" Part 2. Oceania 18, 81-82, 1947.

9. Berndt C. H. and Berndt R. M. Man, Land and Myth in Northern Australia, p. 141. Smith, Sydney, 1970.

10. Berndt C. H. and Berndt R. M. A preliminary report of field work in the Ooldea region, western South Australia. University of Sydney, Sydney (reprinted from Oceania 12-15), 1945.

11. Knight C. Lévi-Strauss and the dragon: Mythologiques reconsidered in the light of an Australian Aboriginal myth. Man 18, 21-50, 1983.

12. Lévi-Strauss C. The Origin of Table Manners, pp. 221-222 and 506. Cape, London, 1978.

13. Stanner W. E. H. On Aboriginal Religion (Oceania Monogr. 11), p. 139. University of Sydney, Sydney, 1966.

14. Berndt R. M. Kunapipi, p. 6. Cheshire, Melbourne, 1951.

15. Buckley T. Menstruation and the power of Yurok women: methods of cultural reconstruction. Am. Ethnol. 9,47-60, 1982.

16. Hugh-Jones S. The Palm and the Pleiades, p. 238. University Press, Cambridge, 1979.

17. Karsten R. The Head-Hunters of Western Amazonas, pp. 220, 376. Societas Scientarium Fennica, Helsingfors, 1935.

18. Hugh-Jones C. From the Milk River, pp. 33-34. University Press, Cambridge, 1979.

19. Bamberger J. The myth of matriarchy. In Women, Culture and Society (Edited by Rosaldo M. Z. and Lamphere L.), pp. 272-276. University Press, Stanford, 1974.

20. Reichel-Dolmatoff G. Amazonian Cosmos, p. 74. Clarendon Press, Oxford, 1968.

21. Gregor T. Mehinaku, p. 255. University Press, Chicago, 1977.

22. Murphy R. F. Social structure and sex antagonism. In Peoples and Cultures of Native South America (Edited by Gross D. R.), pp. $217-218$. Doubleday/Natural History Press, New York, 1973.

23. Berndt R. Love Songs of Arnhem Land. University Press, Chicago, 1976.

24. Munn N. The transformation of subjects into objects in Walbiri and Pitjantjatjara myth. In Australian Aboriginal Anthropology (Edited by Berndt R.). University of Western Australia Press, Nedlands, 1970.

25. Ryan W. M. White Man, Black Man, p. 45. Jacaranda Press, Milton, Queensland, 1969.

26. Elkin A. P. Aboriginal Men of High Degree, p. 20. University of Queensland Press, St Lucia, 1977.

27. Harney W. E. Tales from the Aborigines, pp. 109-110. Hale, London, 1959.

28. Roheim G. The Eternal Ones of the Dream. International University Press, New York, 1945. 
29. Ashley Montagu M. F. Coming into Being Among the Australian Aborigines, p. 301. Routledge, London, 1937.

30. Bettelheim B. Symbolic Wounds. Thames \& Hudson, London, 1955.

31. Gould R. A. Yiwara, p. 112. Collins, London, 1969.

32. Hogbin I. The Island of Menstruating Men. Chandler, Scranton, 1970.

33. Mead M. The mountain Arapesh. Part 2: "Supernaturalism". Anthrop. Pap. Am. Mus. Nat. Hist. 37, 317-451, 1941.

34. Mead M. The Marsalai cult among the Arapesh, with special reference to the rainbow serpent beliefs of the Australian Aboriginal. Oceania 4, 3753, 1933.

35. Spencer B. and Gillen F. J. The Native Tribes of Central Australia, p. 464. Macmillan, London, 1899.

36. de Heusch L. The Drunken King, p. 364. Indiana University Press, Bloomington, 1975.

37. Rivière P. Marriage Among the Trio, p. 268. Clarendon Press, Oxford, 1969. 